www.jmscr.igmpublication.org

Impact Factor 5.84

Index Copernicus Value: 83.27

ISSN (e)-2347-176x ISSN (p) 2455-0450

crossref DOI: _https://dx.doi.org/10.18535/jmscr/v5i7.194

Journal Of Medical Science And Clinical Research

\title{
Adjuvant Therapy in Endometrial Carcinoma: Comparing Outcomes of Low Dose Rate (LDR) and High Dose Rate (HDR) Brachytherapy
}

\author{
Authors \\ Dr Poojar Sridhar ${ }^{1}$, Dr Naveen $T^{2}$, Dr Rahul Loni ${ }^{3}$, Dr Surekha Goyal ${ }^{4}$, Dr Lokesh V $\mathbf{~}^{5}$, \\ C R Vijay ${ }^{6}$ \\ ${ }^{1}$ Assistant Professor, Department of Radiation Oncology Kidwai Cancer Institute, Bengaluru-29 \\ ${ }^{2}$ Associate Professor, Department of Radiation Oncology Kidwai Cancer Institute, Bengaluru-29 \\ ${ }^{3,4}$ Post-Graduate Student, Department of Radiation Oncology Kidwai Cancer Institute, Bengaluru-29 \\ ${ }^{5}$ Professor and Head, Department of Radiation Oncology Kidwai Cancer Institute, Bengaluru-29 \\ ${ }^{6}$ Department of Statistics Kidwai Cancer Institute, Bengaluru-29
}

Corresponding Author

\section{Dr Naveen T}

Associate Professor, Department of Radiation Oncology Kidwai Cancer Institute, Bengaluru-29

Email: drnaveenradonc21@gmail.com

\begin{abstract}
Background: Endometrial cancer is the sixth most common cancer in women worldwide, with 320,000 new cases diagnosed in 2012 with good survival outcomes with adequate treatment. Studies have proven that brachytherapy with or without external beam radiotherapy plays an important role in adjuvant therapy of endometrial cancer. Several studies have been done comparing HDR and LDR brachytherapy in cervical cancer, but very few have been done in endometrial cancer. Thus, we have undertaken this study to compare the outcomes of LDR and HDR brachytherapy in endometrial cancer in terms of overall survival and toxicities.
\end{abstract}

Materials and Methods: 67 cases of endometrial cancer treated in our institute between 2007 to 2014 were retrospectively analysed. All the patients underwent surgery in the form of radical hysterectomy and pelvic lymph node dissection. Depending on the histopathological findings, patients were stratified into risk categories. Depending on which adjuvant chemoradiation followed by brachytherapy or only brachytherapy was given as indicated.

Results: After a median follow-up of 97 months, outcomes were analysed comparing HDR and LDR arm. It was found that both groups had comparable outcomes in terms of overall survival and associated toxicities.

Conclusion: HDR brachytherapy showed comparable results to LDR brachytherapy in terms of overall survival and toxicity. Hence, we recommend that in present era, with advanced techniques of application and optimization, HDR brachytherapy is a preferable technique of treatment.

Keywords: External beam radiotherapy, High dose rate brachytherapy, Low dose rate brachytherapy, Radical hysterectomy. 


\section{INTRODUCTION}

Endometrial cancer is the sixth most common cancer in women worldwide with 320,000 new cases diagnosed in $2012^{(1)}$. It can be easily diagnosed in early stages due to early manifestation of symptoms and thus has an overall improved treatment outcomes, if managed properly. The 5-year survival rates for all stages of endometrial cancer is $69 \%$ and for early stages, it is around $91 \%$. Studies have proved that brachytherapy with or without external beam radiotherapy plays an important role in adjuvant therapy of endometrial cancer. With the advent of HDR brachytherapy, with its several pros and cons over LDR brachytherapy, there have been many speculations over recent years about the efficacy and safety of HDR brachytherapy. Several studies have been done comparing HDR and LDR brachytherapy in cervical cancer, but very few have been done in endometrial cancer. Thus, we have undertaken this study to compare the outcomes of LDR and HDR brachytherapy in endometrial cancer in terms of overall survival.

\section{MATERIAL AND METHODS}

We retrospectively analysed 67 cases of endometrial cancer treated in our institute from 2007 to 2014. All the patients included in this study were thoroughly investigated. Clinical and histological confirmation of tumor was done for all the patients.

Surgery: All the patients underwent total abdominal hysterectomy (TAH) with bilateral salphingo-oophorectomy (BSO) and pelvic lymph-node dissection (PLND). Post-op staging was done for all the patients. Depending on the histopathological findings, patients were stratified into risk categories. Patients received adjuvant chemoradiation followed by brachytherapy or only brachytherapy based on risk category.

Radiation Therapy: Patients were treated with external beam radiotherapy dose of 45-50Gy at 1.8-2 Gy/fr followed by brachytherapy dose having LDR equivalent of 25-30Gy.
Chemotherapy: Concurrent cisplatin $40 \mathrm{mg} / \mathrm{m}^{2}$ was given to the patients based on risk factors Follow up: Patients were followed up through clinical examination and telephonic interview. Maximum follow-up was 105 months in HDR group and 89 months in LDR group.

\section{RESULTS}

Statistical analysis of overall survival and toxicity comparing LDR and HDR group was done. We have used software $\mathrm{R}$ for statistical analysis. To compare the distribution of various stages, grades and modalities of treatment (external beam radiotherapy with brachytherapy or brachytherapy alone), we have used Chi square test and Mann Whitney $\mu$ test to compare the occurrence of toxicities in patients of HDR and LDR group. For calculating overall survival, Kaplan Meir curve was used

Patient Characteristics: Table-1

\begin{tabular}{|c|c|}
\hline \multicolumn{2}{|l|}{ Age (in years) } \\
\hline$<40 \mathrm{yrs}$ & 6 \\
\hline $41-50$ & 24 \\
\hline $51-60$ & 22 \\
\hline$>61$ & 15 \\
\hline \multicolumn{2}{|l|}{ Type of Surgery } \\
\hline TAH+BSO+ bilateral & 63 \\
\hline TAH+BSO & 4 \\
\hline \multicolumn{2}{|l|}{ Stage } \\
\hline IA & 16 \\
\hline IB & 23 \\
\hline II & 16 \\
\hline III & 12 \\
\hline \multicolumn{2}{|l|}{ Grade } \\
\hline I & 6 \\
\hline II & 34 \\
\hline III & 27 \\
\hline \multicolumn{2}{|l|}{\begin{tabular}{|l|} 
Adjuvant treatment \\
\end{tabular}} \\
\hline $\mathrm{EBRT}+\mathrm{BT}$ & 53 \\
\hline BT & 14 \\
\hline
\end{tabular}


Doses delivered in LDR and HDR group:

Table- 2

\begin{tabular}{|l|c|c|c|}
\hline $\begin{array}{l}\text { LDR } \\
\text { (Equivalent } \\
\text { doses in Gy) }\end{array}$ & $\begin{array}{c}\text { HDR } \\
\text { brachytherapy } \\
\text { group }\end{array}$ & $\begin{array}{c}\text { LDR } \\
\text { brachytherapy } \\
\text { group }\end{array}$ & Total \\
\hline $15 \mathrm{~Gy}$ to $0.5 \mathrm{~cm}$ & 1 & 0 & 1 \\
\hline $20 \mathrm{~Gy}$ to $0.5 \mathrm{~cm}$ & 6 & 1 & 7 \\
\hline $25 \mathrm{~Gy}$ to surface & 12 & 4 & 16 \\
\hline 26Gy to $0.5 \mathrm{~cm}$ & 1 & 0 & 1 \\
\hline 30Gy to surface & 15 & 16 & 31 \\
\hline 30Gv to $0.5 \mathrm{~cm}$ & 1 & 2 & 3 \\
\hline 35Gv to surface & 4 & 1 & 5 \\
\hline 37Gy to $0.5 \mathrm{~cm}$ & 1 & 0 & 1 \\
\hline $40 \mathrm{~Gy}$ to $0.5 \mathrm{~cm}$ & 1 & 0 & 1 \\
\hline 55Gy to $0.5 \mathrm{~cm}$ & 1 & 0 & 1 \\
\hline
\end{tabular}

\section{Toxicities:}

Upper GI toxicities: Table-3

\begin{tabular}{|l|c|c|}
\hline Grade & HDR group & LDR group \\
\hline 0 & 8 & 3 \\
\hline I & 17 & 18 \\
\hline II & 17 & 3 \\
\hline III & 1 & 0 \\
\hline IV & 0 & 0 \\
\hline
\end{tabular}

\section{Cystitis: Table-4}

\begin{tabular}{|l|c|c|}
\hline Grade & HDR group & LDR group \\
\hline 0 & 7 & 4 \\
\hline I & 28 & 18 \\
\hline II & 6 & 2 \\
\hline III & 2 & 0 \\
\hline IV & 0 & 0 \\
\hline
\end{tabular}

\section{Proctitis: Table-5}

\begin{tabular}{|l|c|c|}
\hline Grade & HDR group & LDR group \\
\hline 0 & 6 & 5 \\
\hline I & 24 & 8 \\
\hline II & 10 & 11 \\
\hline III & 3 & 0 \\
\hline IV & 0 & 0 \\
\hline
\end{tabular}

\section{Comparison of survival in HDR and LDR group}

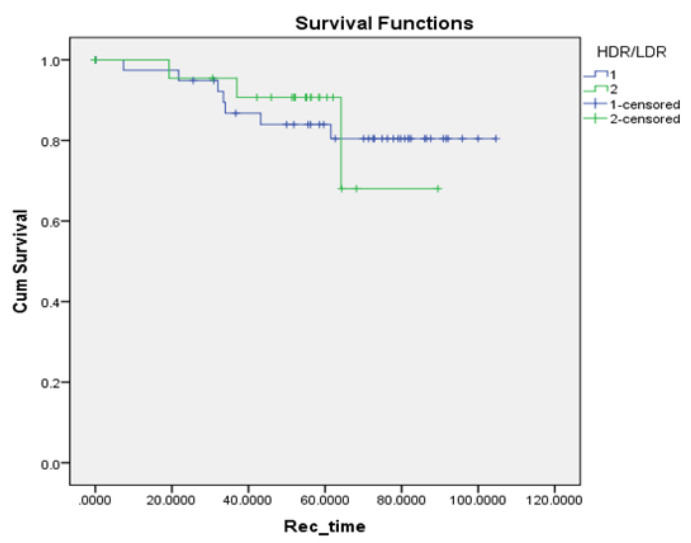

\section{DISCUSSION}

As endometrial carcinoma is one of common malignancies in female with good survival benefits post treatment, several studies have been done to evaluate the role of surgery, radiotherapy and chemotherapy in its treatment. Out of all these modalities, brachytherapy plays an important role in the adjuvant treatment of endometrial carcinoma. Treatment options for patients with early-stage endometrial cancer after hysterectomy include observation, intravaginal RT, or pelvic RT. PORTEC 1 trial evaluated 715 patients, who underwent surgery and had Stage IB grade 2 and 3 and Stage IC, grade 1 and 2. Patients were either kept on observation post surgery or treated with pelvic RT. At the end of 5 years, there was a significant difference in rate of vaginal/pelvis recurrence in favour of pelvic RT though overall survival remained same ${ }^{(2)}$. Similar results were seen in GOG 99 trial and MRC ASTEC trial ${ }^{(3,4)}$. The triad of lack of overall survival advantage, increased toxicity, and high salvage rate of local recurrence for patients who are observed have led many to conclude that pelvic RT is not that beneficial in treatment of such patients.

PORTEC 2 trial established the role of intravaginal therapy in stage IB, IC and IIA patients who were randomized to either pelvic RT or intravaginal brachytherapy. At the end of 3 years, there was no statistically significant difference between two arms in terms of recurrences and overall survival.

The rate of grades 1 and 2 acute GI toxicity was $53 \%$ versus $12 \%$ in favour of intravaginal RT ( $\mathrm{p}<$ $.001)$. This trial showed that intravaginal RT alone is sufficient to control vaginal recurrence even in patients with intermediate- to high-risk features ${ }^{(5)}$. Though, these studies established the role of vaginal brachytherapy in endometrial carcinoma treatment but with the advent of HDR brachytherapy with its several advantages over LDR brachytherapy there were several speculations as to which modality should be preferentially used. No phase III randomized trials have been conducted comparing the results of the 


\section{JMSCR Vol||05||Issue||07||Page 25480-25483||July}

two techniques of brachytherapy.

Thus, we have undertaken this study to compare the results of HDR and LDR brachytherapy in adjuvant treatment of endometrial cancer. In our analysis, we have found that both treatment modalities have comparable results in terms of overall survival and toxicity profile. HDR brachytherapy, is gaining popularity because of The short duration of treatment, more radiation protection, no requirement for administration of general anaesthesia and hospitalization, reduced morbidity due to prolonged bed rest and least displacement of applicator ${ }^{(6)}$.

\section{CONCLUSION}

HDR brachytherapy showed comparable results with LDR brachytherapy in terms of overall survival and associated toxicities. We recommend that in present era, with advanced techniques of application and optimization, HDR brachytherapy is a preferable technique of treatment.

\section{REFERENCES}

1. Ferlay J, Soerjomataram I, Ervik M, Dikshit R, Eser S, Mathers C, Rebelo M, Parkin DM, Forman D, Bray,

2. F. GLOBOCAN 2012, V1.1, Cancer Incidence and mortality worldwide: IARC CancerBase No. 11

3. Creutzberg CL, van Putten WL, Koper PC, et al. Surgery and postoperative radiotherapy versus surgery alone for patients with stage-1 endometrial carcinoma: multicentre randomised trial. PORTEC Study Group. Post-Operative Radiation Therapy in Endometrial Carcinoma. Lancet 2000;355:1404-1411.

4. Keys HM, Roberts JA, Brunetto VL, et al. A phase III trial of surgery with or without adjunctive external pelvic radiation therapy in intermediate risk endometrial adenocarcinoma: a Gynecologic Oncology Group study. Gynecol Oncol 2004; 92(3):744-751.

5. Blake P, Swart AM, Otron $J$, et al.
Adjuvant external beam radiotherapy in the treatment of endometrial cancer (MRC ASTEC and NCIC CTG EN.5 randomised trials): pooled trial results, systematic review, and meta-analysis. Lancet 2009; 373(9658):137-146.

6. Nout RA, Smit VT, Putter $\mathrm{H}$, et al. PORTEC Study Group. Vaginal brachytherapy versus pelvic external beam radiotherapy for patients with endometrial cancer of high-intermediate risk (PORTEC-2): an open-label, noninferiority, randomized trial. Lancet 2010; 375(9717):816-823.

7. Gustavo A Viani, Gastavo B Manta, Edrudo J Stefano, Ligia I de Fendi, Brachytherapy for cervical cancer: lowdose rate or high-dose rate brachytherapya meta-analysis of clinical trials. JECCR 2009. 